\title{
Alkaline Hydrolysis of Y-Substituted Phenyl Phenyl Thionocarbonates: Effect of Changing Electrophilic Center from $C=O$ to $C=S$ on Reactivity and Mechanism
}

\author{
Song-I Kim, Hey-Ran Park, ${ }^{\mathrm{a}}$ and Ik-Hwan Um* \\ Department of Chemistry and Nano Science, Ewha Womans University, Seoul 120-750, Korea. E-mail: ihum@ewha.ac.kr \\ Received October 18, 2010, Accepted November 9, 2010
}

\begin{abstract}
Second-order rate constants $\left(\mathrm{K}_{\mathrm{OH}^{-}}\right)$have been measured spectrophotometrically for reactions of Y-substituted phenyl phenyl thionocarbonates (4a-i) with $\mathrm{OH}^{-}$in $80 \mathrm{~mol} \% \mathrm{H}_{2} \mathrm{O} / 20 \mathrm{~mol} \% \mathrm{DMSO}$ at $25.0 \pm 0.1{ }^{\circ} \mathrm{C}$. The $k_{\mathrm{OH}^{-}}$values for the reactions of $4 \mathbf{a}-\mathbf{i}$ have been compared with those reported previously for the corresponding reactions of $\mathrm{Y}$-substituted phenyl phenyl carbonates (3a-i) to investigate the effect of changing the electrophilic center from $\mathrm{C}=\mathrm{O}$ to $\mathrm{C}=\mathrm{S}$ on reactivity and mechanism. Thionocarbonates $\mathbf{4 a - i}$ are less reactive than the corresponding carbonates $\mathbf{3 a}$-i although 4a-i are expected to be more reactive than 3a-i. The Brønsted-type plot for reactions of 4a-i is linear with $\beta_{\mathrm{lg}}=-0.33$, a typical $\beta_{\mathrm{lg}}$ value for reactions reported to proceed through a stepwise mechanism with formation of an intermediate being the rate-determining step (RDS). Furthermore, the Hammett plot correlated with $\sigma^{\circ}$ constants results in much better linearity than that correlated with $\sigma^{-}$constants, indicating that expulsion of the leaving group is not advanced in the RDS. Thus, alkaline hydrolysis of $\mathbf{4 a - i}$ has been concluded to proceed through a stepwise mechanism with formation of an intermediate being RDS, which is in contrast to the forced concerted mechanism reported for the corresponding reactions of 3a-i. Enhanced stability of the intermediate upon modification of the electrophilic center from $\mathrm{C}=\mathrm{O}$ to $\mathrm{C}=\mathrm{S}$ has been concluded to be responsible for the contrasting mechanisms.
\end{abstract}

Key Words: Alkaline hydrolysis, Polarizability, Concerted mechanism, Stepwise mechanism, Hammett plot

\section{Introduction}

Modification of electrophilic center from $\mathrm{C}=\mathrm{O}$ to $\mathrm{C}=\mathrm{S}$ has generally been understood to increase polarizability of the reaction site, which in turn influences the reactivity and reaction mechanism. ${ }^{1-8}$ The enhanced polarizability is well reflected in ${ }^{13} \mathrm{C}$ NMR spectra, e.g., the chemical shifts reported are 163.8 and 209.8 ppm for the carbon atoms of the $\mathrm{C}=\mathrm{O}$ and $\mathrm{C}=\mathrm{S}$ bonds in 4-nitrophenyl benzoate (1) and thionobenzoate (2), respectively. ${ }^{2}$ Such a large downfield shift suggests that the carbon atom of the $\mathrm{C}=\mathrm{S}$ bond in $\mathbf{2}$ bears more positive charge than that of the $\mathrm{C}=\mathrm{O}$ bond in $\mathbf{1}$. This argument is consistent with the report that $\mathbf{2}$ is $c a$. 14000 fold more reactive than $\mathbf{1}$ toward 4-chlorothiophenoxide (4- $\left.\mathrm{ClC}_{6} \mathrm{H}_{4} \mathrm{~S}^{-}\right){ }^{2 \mathrm{a}}$ The effect of enhanced polarizability on reaction mechanism has also been reported to be significant, e.g., nucleophilic substitution reaction of $\mathbf{1}$ with a series of alicyclic secondary amines proceeds through a zwitterionic tetrahedral intermediate $\mathrm{T}^{ \pm}$while the corresponding reaction of $\mathbf{2}$ proceeds through $\mathrm{T}^{ \pm}$and its deprotonated form $\mathrm{T}^{-} .4,4$

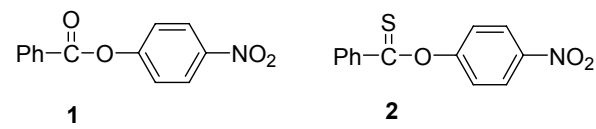

We have recently reported that alkaline hydrolysis of Y-substituted phenyl phenyl carbonates (3a-i) proceeds through a forced concerted mechanism on the basis of the kinetic results, e.g., a linear Brønsted-type plot with $\beta_{\mathrm{lg}}=-0.42$ and excellent linear correlation in the Yukawa-Tsuno plot with $\rho=1.21$ and

${ }^{a}$ Present address: LED Substance Department, LG Display Research Center, Paju 413-811, Korea.

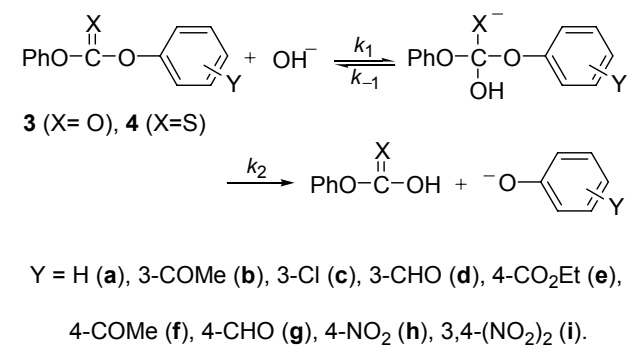

Scheme 1

$r=0.33 .{ }^{9}$ Our study has been extended to alkaline hydrolysis of Y-substituted phenyl phenyl thionocarbonates (4a-i) to get further information on the effect of changing the electrophilic center from $\mathrm{C}=\mathrm{O}$ to $\mathrm{C}=\mathrm{S}$ on reactivity and mechanism (Scheme 1).

\section{Results and Discussion}

All reactions in this study obeyed pseudo-first-order kinetics. Pseudo-first-order rate constants $\left(k_{\text {obsd }}\right)$ were determined from the equation $\ln \left(A_{\infty}-A_{t}\right)=-k_{\mathrm{obsd}} t+C$. The correlation coefficient for the linear regression was usually higher than 0.9995 . The plots of $k_{\text {obsd }} v s$. $\left[\mathrm{OH}^{-}\right]$were linear and passed through the origin, indicating that the contribution of $\mathrm{H}_{2} \mathrm{O}$ to $k_{\text {obsd }}$ is negligible. Thus, the rate low can be expressed as eq (1) and the second-order rate constants $\left(k_{\mathrm{OH}^{-}}\right)$were determined from the slope of the linear plots of $k_{\mathrm{obsd}} v s$. [ $\left.\mathrm{OH}^{-}\right]$. The uncertainty in the $k_{\mathrm{OH}}$ values is estimated to be less than $3 \%$ from replicate runs. The $k_{\mathrm{OH}}$ values determined in this study are summarized in Table 1 together with those reported previously for the corresponding reactions of Y-substituted phenyl phenyl carbonates 
(3a-i) for comparison purpose.

$$
\text { Rate }=k_{\text {obsd }}[\text { Substrate }], \text { where } k_{\text {obsd }}=k_{\mathrm{OH}^{-}}\left[\mathrm{OH}^{-}\right]
$$

Effect of Changing Electrophilic Center from $\mathrm{C}=\mathrm{O}$ to $\mathrm{C}=\mathrm{S}$ on Reactivity. It is generally understood that a $\mathrm{C}=\mathrm{S}$ bond is more polarizable than a $\mathrm{C}=\mathrm{O}$ bond since the overlap between the $2 p$ and $3 p$ orbitals in a $\mathrm{C}=\mathrm{S}$ bond is known to be weaker than that between the $2 \mathrm{p}$ orbitals in a $\mathrm{C}=\mathrm{O}$ bond. ${ }^{6 \mathrm{a}, 8}$ Thus, one might suggest that the resonance contribution of $\mathrm{II}_{\mathrm{a}}$ would be more significant than that of $\mathrm{I}_{\mathrm{a}}$. This argument is consistent with ${ }^{13} \mathrm{C}$ NMR spectra for 4-nitrophenyl phenyl carbonate $\mathbf{3 h}$ and thionocarbonate $\mathbf{4 h}$, i.e., the chemical shifts of the carbon atoms of the $\mathrm{C}=\mathrm{O}$ and $\mathrm{C}=\mathrm{S}$ bonds in $\mathbf{3 h}$ and $\mathbf{4 h}$ reported are 155.3 and 193.4 ppm, respectively. ${ }^{4 \mathrm{~b}}$ Such a large downfield shift suggests that the carbon atom of the $\mathrm{C}=\mathrm{S}$ bond in $\mathbf{4 a - i}$ is more positively charged than that of the $\mathrm{C}=\mathrm{O}$ bond in 3a-i. Accordingly, one might expect that $\mathbf{4 a - i}$ are more reactive than 3a-i.

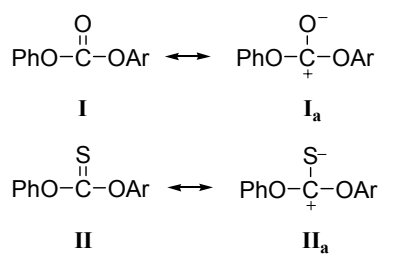

However, Table 1 shows that $\mathbf{4 a - i}$ are less reactive than $\mathbf{3 a - i}$ toward $\mathrm{OH}^{-}$ion. This is consistent with the report that $\mathbf{2}$ is less reactive than 1 toward $\mathrm{OH}^{-2}$. Thus, one can suggest that the reactivity of polarizable substrates is strongly dependent on the nature of nucleophiles, i.e., the low reactivity of $\mathrm{OH}^{-}$ion toward polarizable 4a-i appears to be in accordance with the hard-soft acids and bases (HSAB) principle since $\mathrm{OH}^{-}$is nonpolarizable and a hard base. ${ }^{10}$ This argument is consistent with our previous reports that $\mathbf{2}$ is significantly more reactive than $\mathbf{1}$ toward polarizable nucleophiles (e.g., 4- $\mathrm{ClC}_{6} \mathrm{H}_{4} \mathrm{~S}^{-}$and $\mathrm{N}_{3}{ }_{3}$ ), while the former is less reactive than the latter toward $\mathrm{OH}^{-}$ion. ${ }^{2}$

Effect of Changing Electrophilic Center from $C=O$ to $C=S$ on Mechanism. To investigate the reaction mechanism, Brønsted-

Table 1. Summary of Second-Order Rate Constants for Reactions of Y-Substituted Phenyl Phenyl Carbonates (3a-i) and Thionocarbonates (4a-i) with $\mathrm{OH}^{-}$in $80 \mathrm{~mol} \% \mathrm{H}_{2} \mathrm{O} / 20 \mathrm{~mol} \% \mathrm{DMSO}$ at $25.0 \pm 0.1{ }^{\circ} \mathrm{C}^{a}$

\begin{tabular}{|c|c|c|c|c|}
\hline \multirow{2}{*}{ entry } & \multirow{2}{*}{$\mathrm{Y}$} & \multirow{2}{*}{$\mathrm{p} K_{\mathrm{a}}$} & \multicolumn{2}{|c|}{$k_{\mathrm{OH}^{-}} / \mathrm{M}^{-1} \mathrm{~s}^{-1}$} \\
\hline & & & 3 & 4 \\
\hline $\mathbf{a}$ & $\mathrm{H}$ & 9.95 & 7.31 & 0.534 \\
\hline $\mathbf{b}$ & 3-COMe & 9.19 & 21.2 & 1.37 \\
\hline c & $3-\mathrm{Cl}$ & 9.02 & 21.4 & 1.30 \\
\hline d & 3-CHO & 8.98 & 25.7 & 1.63 \\
\hline e & 4-COOEt & 8.50 & 35.1 & 1.72 \\
\hline f & 4-COMe & 8.05 & 34.7 & 1.84 \\
\hline g & 4-CHO & 7.66 & 50.8 & 2.25 \\
\hline h & $4-\mathrm{NO}_{2}$ & 7.14 & 140 & 4.70 \\
\hline $\mathbf{i}$ & $3,4-\left(\mathrm{NO}_{2}\right)_{2}$ & 5.42 & 794 & 24.1 \\
\hline
\end{tabular}

${ }^{a}$ The kinetic data for the reactions of 3a-i were taken from ref. 9 . type plot has been constructed for the reactions of 4a-i. As shown in Figure 1, the plot is linear with $\beta_{\mathrm{lg}}=-0.33$ although some points deviate slightly from the linearity. The plot for the corresponding reactions of $\mathbf{3 a - i}$ (inset of Figure 1) is also linear with $\beta_{\mathrm{lg}}=-0.42$, which is close to a lower limit for a concerted mechanism. ${ }^{3-6,11-14}$ A $\beta_{\text {lg }}$ value of -0.33 is typical for reactions reported previously to proceed through a stepwise mechanism with formation of an intermediate being rate-determining step (RDS). ${ }^{3-6,11-14}$ Thus, one can suggest that the reactions of $\mathbf{4 a - i}$ proceed through a stepwise mechanism in which formation of an intermediate is RDS.

To examine the above argument that alkaline hydrolysis of 4a-i proceed through a stepwise mechanism, Hammett plots have been constructed using $\sigma^{-}$and $\sigma^{\circ}$ constants. If the reaction of 4a-i proceeds through a concerted mechanism, a partial negative charge would develop on the oxygen atom of the leaving Y-substituted phenoxide. Since such a negative charge can be delocalized on the substituent $\mathrm{Y}$ through resonance interactions, $\sigma^{-}$constants would result in better correlation than $\sigma^{\circ}$ constants. In contrast, if the reaction proceeds through a stepwise mechanism, expulsion of the leaving group should occur after RDS. This is because $\mathrm{OH}^{-}$is much more basic and a poorer leaving group than Y-substituted phenoxide. Accordingly, if the reaction proceeds through a stepwise mechanism, no negative charge would develop on the oxygen atom of Y-substituted phenoxide of $4 \mathbf{a}-\mathbf{i}$ at the transition state. In this case, one might expect that $\sigma^{\circ}$ constants should result in better correlation than $\sigma^{-}$constants. As shown in Figures 2A and 2B, the Hammett plot correlated with $\sigma^{\text {o }}$ constants (i.e., A) shows much better linear correlation than that correlated with $\sigma^{-}$constants (i.e., B), indicating that no negative charge is developing on the leaving group in the transition state. Thus, one can conclude that alkaline hydrolysis of 4a-i proceeds through a stepwise mechanism, in which leaving-group departure occurs after RDS.

Alkaline hydrolysis of $\mathbf{3 a - i}$ has recently been reported to

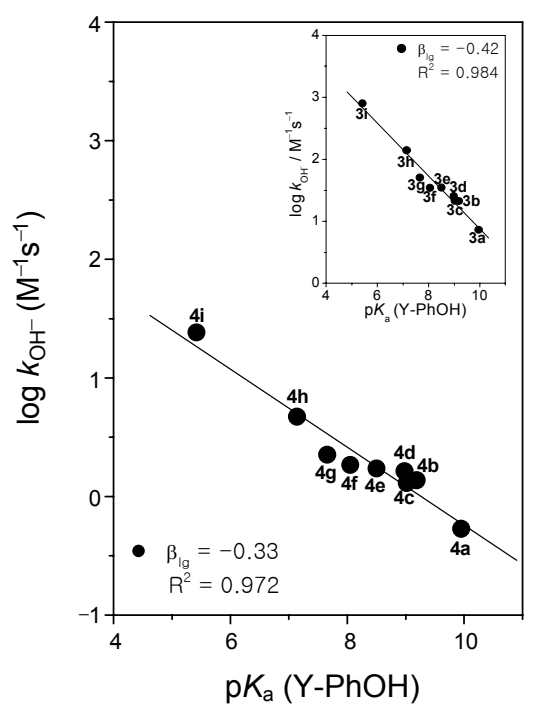

Figure 1. Brønsted-type plots for alkaline hydrolysis of Y-substituted phenyl phenyl thionocarbonates 4a-i and Y-substituted phenyl phenyl carbonates 3a-i (inset) in $80 \mathrm{~mol} \mathrm{\%} \mathrm{H}_{2} \mathrm{O} / 20 \mathrm{~mol} \% \mathrm{DMSO}$ at $25.0 \pm$ $0.1{ }^{\circ} \mathrm{C}$. The identity of points is given in Table 1 . 
(A)

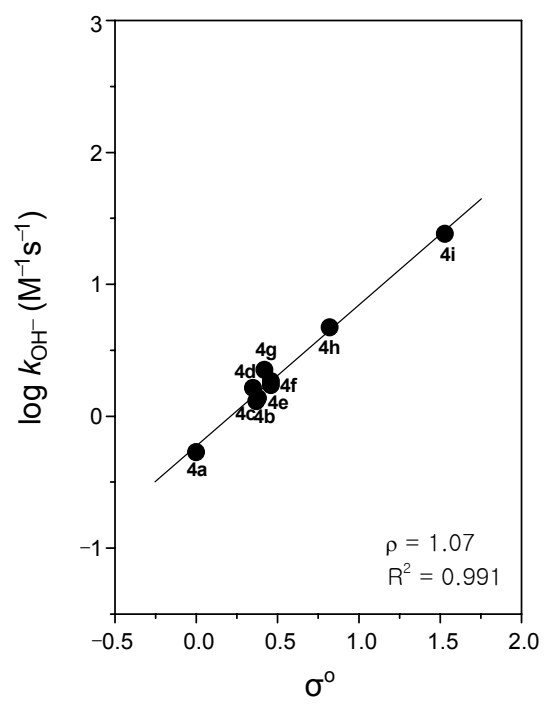

(B)

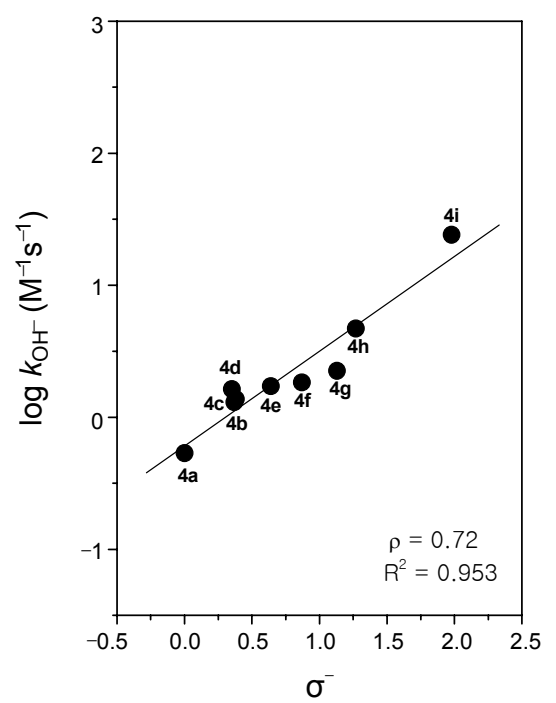

Figure 2. Hammett plots correlated with $\sigma^{\circ}(\mathrm{A})$ and $\sigma^{-}(\mathrm{B})$ constants for reactions of Y-substituted phenyl phenyl thionocarbonates 4a-i with $\mathrm{OH}^{-}$in $80 \mathrm{~mol} \% \mathrm{H}_{2} \mathrm{O} / 20 \mathrm{~mol} \% \mathrm{DMSO}$ at $25.0 \pm 0.1{ }^{\circ} \mathrm{C}$. The identity of points is given in Table 1 .

proceed through a concerted mechanism on the basis of the fact that the Yukawa-Tsuno plot exhibits an excellent linearity with $\rho=1.21$ and $r=0.33$. ${ }^{9}$ Although the kinetic result was consistent with a concerted mechanism, a possibility that the reaction of 3a-i with $\mathrm{OH}^{-}$proceeds through a forced concerted mechanism with a highly unstable intermediate (e.g., III) has not been excluded. ${ }^{9}$

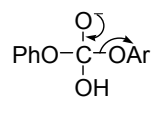

III

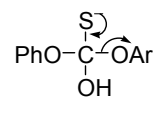

IV
In contrast, one might expect that intermediate IV would be less unstable than III since the ability of $\mathrm{C}^{-} \mathrm{S}^{-}$in IV to form a $\mathrm{C}=\mathrm{S}$ bond is weaker than that of $\mathrm{C}^{-} \mathrm{O}^{-}$in III to form a $\mathrm{C}=\mathrm{O}$ bond due to a weaker overlap between the $2 p$ and $3 p$ orbitals in the $\mathrm{C}=\mathrm{S}$ bond compared to that between the $2 \mathrm{p}$ orbitals in the $\mathrm{C}=\mathrm{O}$ bond. ${ }^{6 \mathrm{a}, 8}$ Thus, one can suggest that the difference in stability of intermediates III and IV is responsible for the difference in mechanisms, i.e., a forced concerted mechanism for the reactions of $\mathbf{3 a - i}$ and a stepwise pathway for those of $\mathbf{4 a - i}$.

\section{Conclusions}

The current study has allowed us to conclude the following: (1) Thionocarbonates $\mathbf{4 a - i}$ are less reactive than carbonates 3a-i although 4a-i are expected to be more reactive than 3a-i. (2) The Brønsted-type plot for the current reactions of $\mathbf{4 a - i}$ is linear with $\beta_{\mathrm{lg}}=-0.33$, which is typical for reactions reported previously to proceed through a stepwise mechanism with formation of an intermediate being RDS. (3) The Hammett plot correlated with $\sigma^{\circ}$ constants results in much better linearity than that correlated with $\sigma^{-}$constants, indicating that no negative charge is developing on the leaving group in the transition state. (4) The alkaline hydrolysis of $\mathbf{4 a - i}$ is concluded to proceed through a stepwise mechanism, in which leaving-group departure occurs after the RDS. (5) Modification of the electrophilic center from $\mathrm{C}=\mathrm{O}$ to $\mathrm{C}=\mathrm{S}$ increases stability of the intermediate, which is responsible for the contrasting mechanisms, e.g., a forced concerted mechanism for the reactions of $\mathbf{3 a}-\mathbf{i}$ and a stepwise pathway for those of $\mathbf{4 a - i}$.

\section{Experimental}

Materials. Y-Substituted phenyl phenyl thionocarbonates (4a-i) were readily prepared from the reaction of phenyl chlorothionoformate with Y-substituted phenol in anhydrous ether under the presence of triethylamine. DMSO and other chemicals were of the highest quality available. Doubly glass distilled water was further boiled and cooled under nitrogen just before use. Due to low solubility of $\mathbf{4 a - i}$ in pure water, aqueous DMSO (80 $\mathrm{mol} \% \mathrm{H}_{2} \mathrm{O} / 20 \mathrm{~mol} \% \mathrm{DMSO}$ ) was used as the reaction medium.

Kinetics. The kinetic study was performed using a UV-vis spectrophotometer equipped with a constant temperature circulating bath to maintain the reaction mixture at $25.0 \pm 0.1{ }^{\circ} \mathrm{C}$. The reactions were followed by monitoring the appearance of Y-substituted phenoxide ion. All the reactions were carried out under pseudo-first-order conditions.

Typically, the reaction was initiated by adding $5 \mu \mathrm{L}$ of a $0.02 \mathrm{M}$ solution of 4a-i in acetonitrile to a $10-\mathrm{mm}$ quartz UV cell containing $2.50 \mathrm{~mL}$ of the thermostated reaction mixture made up of solvent and aliquot of $\mathrm{NaOH}$ stock solution. All solutions were transferred by gas-tight syringes. Generally, the $\mathrm{NaOH}$ concentration in the reaction mixtures was varied over the range $(5-100) \times 10^{-3} \mathrm{M}$, while the substrate concentration was $c a$. $4 \times 10^{-5} \mathrm{M}$. Pseudo-first-order rate constants $\left(k_{\text {obsd }}\right)$ were calculated from the equation, $\ln \left(A_{\infty}-A_{t}\right)=-k_{\mathrm{obsd}} t+C$. The plots of $\ln \left(A_{\infty}-A_{t}\right)$ vs. time were linear over $90 \%$ of the total reaction. Usually, five different $\mathrm{NaOH}$ concentrations were employed and replicate values of $k_{\text {obsd }}$ were determined to obtain the second-order rate constants $\left(k_{\mathrm{OH}^{-}}\right)$from the slope of linear plots of $k_{\text {obsd }} v s$. NaOH concentrations.

Products Analysis. Y-Substituted phenoxide was liberated quantitatively and identified as one of the products in the reaction of $4 \mathbf{a}-\mathbf{i}$ by comparison of the UV-vis spectrum after com- 
pletion of the reaction with that of authentic sample under the same reaction condition.

Acknowledgments. This research was supported by Basic Science Research Program through the National Research Foundation of Korea (NRF) funded by the Ministry of Education, Science and Technology (2009-0075488). S. I. Kim and H. R. Park are also grateful for the BK 21 Scholarship.

\section{References}

1. (a) Scheithauer, S.; Mayer, R. Chem. Ber. 1965, 98, 838-843. (b) Bruice, P.; Mautner, S. J. Am. Chem. Soc. 1973, 95, 1582-1586. (c) Pedersen, B. S.; Scheibye, S. Nilsson, N. H.; Lawesson, S. O. Bull. Soc. Chim. Belg. 1978, 87, 223-228.

2. (a) Um, I. H.; Lee, J. Y.; Bae, S. Y.; Buncel, E. Can. J. Chem. 2005, 83, 1365-1371. (b) Um, I. H.; Han, J. Y.; Buncel, E. Chem. Eur. J. 2009, 15, 1011-1017. (c) Um, I. H.; Kim, E. H.; Lee, J. Y. J. Org. Chem. 2009, 74, 1212-1217.

3. (a) Um, I. H.; Hwang, S. J.; Yoon, S.; Jeon, S. E.; Bae, S. K. J. Org. Chem. 2008, 73, 7671-7677. (b) Um, I. H.; Hwang, S. J.; Baek, M. H.; Park, E. J. J. Org. Chem. 2006, 71, 9191-9197. (c) Um, I. H.; Han, H. J.; Back, M. H.; Bae, S. Y. J. Org. Chem. 2004, 69, 6365-6370. (d) Um, I. H.; Lee, S. E.; Kwon, H. J. J. Org. Chem. 2002, 67, 8999-9005.

4. (a) Um, I. H.; Yoon, S.; Park, H. R.; Han, H. J. Org. Biomol. Chem. 2008, 6, 1618-1624. (b) Um, I. H.; Kim, E. Y.; Park, H. R.; Jeon, S. E. J. Org. Chem. 2006, 71, 2302-2306.

5. (a) Castro, E. A.; Cubillos, M.; Santos, J. G. J. Org. Chem. 1997, 61, 3501-3505. (b) Castro, E. A.; Cubillos, M.; Santos, J. G.; Tellez, Jimena. J. Org. Chem. 1997, 62, 2512-2517. (c) Castro, E. A.; Santos, J. G.; Tellez, Jimena.; Umana, M. I. J. Org. Chem. 1997, 62, 6568-6574. (d) Castro, E. A.; Saavedra, C.; Santos, J. G.; Umana, M. I. J. Org. Chem. 1999, 64, 5401-5407.
6. (a) Oh, H. K.; Woo, S. Y.; Shin, C. H.; Park, Y. S.; Lee, I. J. Org. Chem. 1997, 62, 5780-5784. (b) Oh, H. K.; Yang, J. H.; Sung, D. D. J. Chem. Soc., Perkin Trans. 2 2000, 101-105. (c) Oh, H. K.; Kim, S. K.; Cho, I. H.; Lee, H. W.; Lee, I. J. Chem. Soc., Perkin Trans. 2 2000, 2306-2310.

7. (a) Campbell, P.; Lapinskas, B. A. J. Am. Chem. Soc. 1977, 99, 5378-5382. (b) Campbell, P.; Nashed, N. T. J. Am. Chem. Soc. 1982, 104, 5221-5226.

8. (a) Hill, S. V.; Thea, S.; Williams, A. J. Chem. Soc., Perkin Trans. 1983, 2, 437-446. (b) Oh, H. K.; Kim, S. K.; Lee, H. W.; Lee, I. New J. Chem. 2001, 25, 313-317. (c) Oh, H. K.; Kim, S. K.; Lee, H. W.; Lee, I. J. Chem. Soc., Perkin Trans. 2 2001, 1753-1757.

9. Kim, S. I.; Hwang, S. j.; Jung, E. M.; Um, I. H. Bull. Korean Chem. Soc. 2010, 31, 2015-2018.

10. (a) Pearson, R. G. J. Am. Chem. Soc. 1963, 85, 3533-3539. (b) Ho, T. L. In Hard andSoft Acids and Bases; Pearson, R. G. Ed.; Academic Press: New York, 1977.

11. (a) Um, I. H.; Im, L. R.; Kim, E. H.; Shin, J. H. Org. Biomol. Chem. 2010, 8, 3801-3806. (b) Um, I. H.; Lee, J. Y.; Ko, S. H.; Bae, S. K. J. Org. Chem. 2006, 71, 5800-5803. (c) Um, I. H.; Kim, K. H.; Park, H. R.; Fujio, M. Tsuno, Y. J. Org. Chem. 2004, 69, 39373942. (d) Um, I. H.; Min, J. S.; Ahn, J. A.; Hahn, H. J. J. Org. Chem. 2000, 65, 5659-5663. (e) Um, I. H.; Min, J. S.; Lee, H. W. Can. J. Chem. 1999, 77, 659-666.

12. (a) Um, I. H.; Han, J. Y.; Shin, Y. H. J. Org. Chem. 2009, 74, 30733078. (b) Um, I. H.; Akhtar, K.; Shin, Y. H.; Han, J. Y. J. Org. Chem. 2007, 72, 3823-3829. (c) Um, I. H.; Shin, Y. H.; Han, J. Y.; Mishima, M. J. Org. Chem. 2006, 71, 7715-7720.

13. (a) Jencks, W. P.; Gilchrist, M. J. Am. Chem. Soc. 1968, 90, 26222637. (b) Jencks, W. P. Chem. Rev. 1985, 85, 511-527. (c) Jencks, W. P.; Chem. Soc. Rev. 1981, 10, 345-375. (d) Satterthwait, A. C.; Jencks, W. P. J. Am. Chem. Soc. 1974, 96, 7018-7031.

14. (a) Menger, F. M.; Smith, J. H. J. Am. Chem. Soc. 1972, 94, 38243829. (b) Bruice, T. C.; Hegarty, A. F.; Felton, S. M.; Donzel, A.; Kundu, N. G. J. Am. Chem. Soc. 1970, 92, 1370-1374. 